\title{
Supporting Teachers in Times of Change: The Job Demands- Resources Model and Teacher Burnout During the COVID-19 Pandemic
}

\author{
Laura J. Sokal ${ }^{1}$, Lesley G. Eblie Trudel ${ }^{1}$, Jeff C. Babb ${ }^{1}$ \\ ${ }^{1}$ University of Winnipeg, Canada \\ Correspondence: Laura J. Sokal, University of Winnipeg, Canada. \\ Received: July 16, 2020 \\ Accepted: August 10, 2020 \\ Online Published: August 11, 2020 \\ doi:10.11114/ijce.v3i2.4931 \\ URL: https://doi.org/10.11114/ijce.v3i2.4931
}

\begin{abstract}
Burnout in teachers has been broadly investigated, but no studies have investigated burnout in teachers during a pandemic. The current study is based on a survey of 1278 Canadian teachers and examined whether the Job Demands-Resources model was a useful lens for examining teacher burnout in this unprecedented context. Results supported the model in general terms in that most demands were most strongly correlated with the initial exhaustion stage of burnout. However, not all resources were most strongly associated with the later stages of burnout, suggesting that the examination of specific resources in the context of a pandemic as opposed to examining resources together as a latent variable contributes to development of a more refined model. Suggestions for supporting teachers' welfare are provided.
\end{abstract}

Keywords: burnout, teachers, demands, resources, pandemic, model

\section{Introduction}

\subsection{Introduction of the Problem}

The COVID-19 pandemic created a necessity for school systems to quickly pivot to remote teaching, resulting in significant, global changes to typical instructional practices. Teachers, as the front-line workers in the education system, were tasked with quickly implementing the new teaching practices in ways that promoted student learning while maximizing student safety. In their report to UNESCO, Holmes and her colleagues (2020) stressed the importance of studying the psychological effects of the pandemic, especially the effects on front-line workers, so that the knowledge gained may be applied in future periods of pandemics. Given that subsequent waves of COVID-19 are expected, the goal of this research study was to determine the factors associated with teacher burnout and resilience during the first wave of COVID-19, with the intent of making evidence-based recommendations for better supporting teachers to meet the next wave of the pandemic.

Decades of research has confirmed that teaching is a stressful profession (Johnson et al. 2005; Skaalvik \& Skaalvik, 2015; Van Veldhoven 1996). Van Veldhoven (1996) identified symptoms of stress as negative emotions, discontent, and tension. When teachers experience high stress levels, the outcomes include lower quality instruction, negative teacher well-being and health, and eventually teacher attrition and burnout (Alarcon, 2011; Clunies-Ross, Little, \& Kienhuis, 2008, Harmsen, Helms-Lorenz, Maulana, \& van Veen, 2018). Moreover, teacher stress and poor well-being negatively affect student achievement (Arens \& Morin, 2016; Collie \& Martin, 2017; Klusmann, Richter, \& Lüdtke, 2016). The good news is that although the job demands of teaching may cause stress, research by Jennings and Greenberg (2009) indicated that effective stress management leads to resilient teachers who remain effective despite challenges. Ott, Hiebert, Rodger, \& Leschiel (2017) defined resilience as the ability to cope and grow through adversity. We were interested in answering the call of Holmes et al. (2020) to understand the psychological effects of teaching during the pandemic, with a specific focus on the relationship between job demands, job resources, stress, resilience, and burnout. Kyriacou (2001) recognized that research was needed to assess the influence of various external and internal factors on teacher stress, and such research is even more imperative during the current pandemic, when we depend on the continued strength and well-being of teachers as the front-line workers of the educational system.

\subsection{The Job Demands-Resources Model}

The Bakker and Demerouti (2007) job demands-resources model (JD-R model) is a transactional model that has been used to examine teacher stress. Job demands were defined as "physical, psychological, social, or organizational aspects 
of the job that require sustained physical and/or psychological (cognitive and emotional) effort or skills" (Bakker \& Demerouti, 2007, p. 312). Bakker \& Demerouti (2007) further defined job resources as "physical, psychological, social, or organizational aspects of the job that are either functional in achieving work goals, reducing job demands and the associated physiological and psychological costs, or [in] stimulating personal growth, learning, and development" (p. 312).

Researchers have recognized that stress is the result of the appraised mismatch between job demands and resources (Bakker \& Demerouti, 2007; McCarthy, Lambert, Lineback, Fitchett, \& Baddouh, 2015). When there is a balance of job demands with job resources, teachers can successfully meet their job demands. In contrast, stress is the result of the appraised mismatch between job demands and resources (Bakker \& Demerouti, 2007; McCarthy et al., 2015), and may eventually lead to teacher burnout and attrition (Harmsen et al., 2018; Maulana, Helms-Lorenz, \& van de Grift, 2015).

The JD-R model is an effective lens for examining the dynamic relationship between burnout and resilience during the COVID-19 pandemic. This model has undergone revision (Bakker \& Demerouti, 2007; Demerouti, Bakker, Nachreiner, \& Schaufeli, 2001). Its revised version (Bakker \& Demerouti, 2007), which is used in the current study, is improved over the previous version by considering internal resources (called 'personal resources' by Bakker and Demerouti, 2007, and by Taris, Leisink, \& Schaufeli, 2017) in addition to contextual job resources used to meet the job demands. This enhanced version further recognizes the importance of examining job context, as it is the subjective appraisals by individuals in that context which will determine which resources are most effective in the face of particular demands (Taris et al., 2017). This aspect of the model is especially salient during the COVID-19 pandemic, as the study of teacher stress in this unprecedented environment was not previously possible.

The JD-R model is also sensitive to how the balance of demands versus resources might change over time (Bakker \& Demerouti, 2007). Even those teachers who successfully navigated the first wave of the pandemic well may find that, over time, their resources become depleted. When this occurs, teachers burn out. Burning out, which has been copiously studied in other contexts of teaching prior to the COVID-19 pandemic, is a progressive process associated with three consecutive stages: emotional exhaustion with perceptions of having no resources left to meet the needs; followed by cynicism toward students, parents, and/or the school community; and finally by reduced accomplishment in teaching (Alarcon, 2011; Maslach \& Jackson, 1981). By using the JD-R model (Bakker \& Demerouti, 2007), we were able to determine how teachers interpret demands, contextual resources, and personal resources at different stages of burn out during the first wave of the COVID-19 pandemic.

\subsection{Potential Variables that Affect Teacher Stress and Burnout}

An advantage of the JD-R model (Bakker \& Demerouti, 2007) is that it is responsive to teaching demands in a variety of contexts and has the flexibility to incorporate variables that are unique or relevant to a specific context. Although a myriad of factors may potentially contribute to teacher stress during the current pandemic, 20 specific variables within two major categories of job demands and job resources are examined in the current study.

The current research examines five work demands: time management (Crawford, LePine, \& Rich, 2010), technology (AlFudail \& Mellar, 2008), expectations of parents (Boldrini, Sappa, \& Aprea, 2019), balance of home and work life (Boldrini, Sappa, \& Aprea, 2019), and lack of resources (Crawford, LePine, \& Rich, 2010). In reference to the stages of burnout, Alarcon (2011) suggested that job demands will have the strongest correlations with emotional exhaustion, followed by cynicism, then reduced accomplishment in teaching.

The JD-R model recognized a dynamic systemic relationship where "properties of the work situation, as well as the characteristics of the individual, can buffer the effects of the stressor" (Bakker \& Demerouti, 2007, p. 314). Thus, "properties of the work situation" such as support from the school principal (Collie \& Martin, 2017), peer support (Collie \& Martin, 2017), and professional development (Boldrini et al., 2019) on both teaching methods and technology are examined to determine their relationship to the stages of teacher burnout. We also consider contextual resources in terms of teacher-directed actions that may decrease stress including physical self-care (exercise, sleep, healthy eating) and emotional self-care (meditation, prayer, counselling, journaling and mindfulness) and the relationships of such actions with teacher burnout stages. In contrast to the relationship between demands and burnout, Alarcon (2011) demonstrated that resources have the strongest correlation with accomplishment in teaching, followed by cynicism, then emotional exhaustion.

\subsection{Hypotheses}

In light of the current literature regarding the JD-R model and the relationship between job demands, job resources, and teacher burnout, we predicted:

H1: Job demands would be most strongly correlated with teacher exhaustion, followed by cynicism, then accomplishment.

H2: Job resources would be most strongly correlated with teacher accomplishment, followed by cynicism, then exhaustion. 


\section{Method}

\subsection{Design}

The current study was approved by the primary investigator's University Human Research Ethics Board as meeting the standards of the TCPS-2. It was funded by a SSHRC Engage grant managed by the primary investigator's university. The study is built on a survey-based design. The survey was conducted between April 22 and May 6, 2020, a time when all schools in Canada had completed the spring break, and teachers in Canada were teaching remotely. In terms of recruitment, the online survey link was shared through email with professors at universities in Canada with the request that they share it with their colleagues employed in the field of kindergarten to grade twelve teaching in Canada. The snowball method of sampling was used, as each participant was asked to share the link with their own contacts. Teachers who clicked on a link accessed a consent form and an online survey housed on Survey Monkey. The 92-question survey was anonymous and required approximately 15 minutes to complete. Participants were asked to generate a codename to be used to link their survey data to subsequent survey data collection in June and September 2020, as part of the larger longitudinal study.

\subsection{Measures}

\subsubsection{Demographics}

Teachers were asked to describe various demographic characteristics such as gender, age, years of teaching experiences, current subject and grades, and level of education.

\subsubsection{Stress and Burnout}

Teachers were asked to indicate their current stress levels on three measures. Stress and coping were measured using two global statements, as validated by Eddy, Herman, \& Reinke (2019). They were, "How stressful is your job right now?" (measured on a 10-point Likert scale with 1 being low and 10 being high) and "How well are you coping with the stress of your job right now?" (measured on a 10-point Likert scale with 1 being low and 10 being high). Teacher stress was also measured using the Maslach Burnout Inventory for Educators (Maslach \& Jackson, 1981). This is a 22-item instrument that measures the characteristics of burnout, including exhaustion, cynicism, and personal accomplishment (Maslach, Jackson, \& Schwab, 1996). It uses a 7-point Likert scale indicating the frequency with which educators agrees with the statements: 0 (never); 1 (a few times since beginning teaching at home); 2 (once a month or less); 3 (a few times a month); 4 (one a week); 5 (a few times a week) 6 (every day). Three examples of statements are: "I feel emotionally drained from work" (exhaustion); "I don't really care what happens to some students" (cynicism); and "I have accomplished many worthwhile things in this job" (accomplishment).

\subsubsection{Job Demands and Resources}

Teachers were given the opportunity to indicate job demands and resources that are implicated in the closure of schools and the pivot to online teaching. They were provided with a list of five anticipated demands -parental expectations and work/life balance (Boldrini, et al., 2019), time management, and lack of resources (Crawford, et al., 2010), and technology (Al-Fudail \& Mellar, 2008)-- and asked to indicate the degree to which they perceived each as contributing to their current job demands. Likewise, teachers were provided with a list of fifteen potential resources (both contextual and personal, including, for examples, support from administrators, support from colleagues, and self-care activities such as mindfulness [Boldrini et al., 2019]) and instructed to indicate the degree to which they perceived each as contributing to support of their teaching. Both resources and demands were measured on a Likert scale ranging from 1 (not at all) to 6 (a great deal).

\subsection{Participants}

In total, 1327 people completed the survey. People who indicated they were not teachers (e.g. administrators, clinicians, etc.) were excluded from the analyses, resulting in 1278 participants. There was representation from all provinces and one territory of Canada, with the most participants from Manitoba $(n=595,46.6 \%)$, Nova Scotia $(n=335,26.2 \%)$, or New Brunswick $(n=107,8.4 \%)$. Most of the teachers were female $(n=1069,83.8 \%)$. Age and experience with teaching were distributed across several categories. In terms of age, $2.5 \%$ were under $25,15 \%$ were $26-30,32.1 \%$ were $31-40$, $32.9 \%$ were $41-50$, and $17.5 \%$ were over 50 . With respect to teaching experience, $3.2 \%$ had under 1 year, $16.8 \%$ had $2-5$ years, $18.8 \%$ had $6-10$ years, $20.4 \%$ had $11-15$ years, and $40.8 \%$ had over 15 years. In terms of education, the majority of teachers held a Bachelor's degree in education (53.4\%) while 17.6\% had some graduate schooling, and $28.5 \%$ held a Master's degree.

\section{Results}

In terms of global ratings of stress, the mean self-reported rating was 6.82 on a scale of 1 to 10 , with ten indicating high stress. The mean self-reported rating for coping was 5.84 on a scale of 1 to 10 , with ten denoting high coping. Together these scores indicate that the participants were not perceiving adequate balances between demands and resources. With 
respect to the Maslach Burnout scores, the mean exhaustion score was 3.35 on a scale of 0 to 6 , with 6 denoting high exhaustion. This mean indicates the participants were experiencing exhaustion a few times a month to once a week, 3.35 points away from the most desirable score of zero (never). The mean cynicism score was 1.46 on a scale of 0 to 6 , with 6 corresponding to high depersonalization/cynicism. This mean score indicates the participants were experiencing cynicism rarely to once a month or less, 1.46 points away from the most desirable score of zero (never). In terms of accomplishment, the mean score was 3.42 on a scale of 0 to 6 , with 6 indicating high accomplishment. This mean score indicates the participants were experiencing a sense of accomplishment a few times a month to once a week, 2.58 points away from the most desirable score of 6 (every day). Together, these scores suggest that the participants were functioning at a level of exhaustion that could be interpreted as indicating that they were in the early stages of burnout.

\subsection{Hypothesis 1}

Hypothesis one predicted that demands would be most strongly correlated with teacher exhaustion, followed by cynicism, then accomplishment. Two-tailed tests of Pearson correlations indicated that hypothesis one was partially supported. Four of the five job demands were most strongly correlated with exhaustion, and next most strongly correlated with cynicism, as predicted by Alarcon (2011). However, lack of resources was most strongly (negatively) correlated with accomplishment. See Table 1, bolded items.

Table 1. Correlations between Demands and Burnout

\begin{tabular}{llll}
\hline Demands & \multicolumn{3}{c}{ Burnout } \\
\cline { 2 - 4 } & Exhaustion & Cynicism & Accomplishment \\
\hline & & & \\
D1. Time management &. $\mathbf{4 4 5 * *}$ & $.101^{* *}$ & .032 \\
D2. Technology issues & $\mathbf{. 3 0 6 * *}$ & .051 & $-.059^{*}$ \\
D3. Parents &. $\mathbf{2 0 1 * *}$ & $.071^{*}$ & $-.070^{*}$ \\
D4. Balancing home/teaching & $\mathbf{. 3 5 6 * *}$ & $.131^{* *}$ & $-.072^{*}$ \\
D5. Lack of resources & $.232^{* *}$ & $.124^{* *}$ & $\mathbf{- . 2 3 9 * *}$ \\
\hline
\end{tabular}

Note: Higher levels of burnout are indicated by higher levels of exhaustion and cynicism, but lower levels of accomplishment.

**Correlation is significantly different from zero at the .01 level (2-tailed).

*Correlation is significantly different from zero at the .05 level (2-tailed).

\subsection{Hypothesis 2}

Hypothesis two predicted that resources would be most strongly correlated with teacher accomplishment, followed by cynicism, then exhaustion. This hypothesis was partially supported. We found that eight of fifteen resources had the strongest correlation with accomplishment (See Table 2, bolded items for strongest correlations). However, we also found that one of the resources had the strongest (negative) correlation with cynicism and six resources had the strongest (positive) correlations with exhaustion, neither of which was predicted as a pattern by previous research (Alarcon, 2011; Demerouti, et al., 2001; Jagodics \& Szabo, 2014). Five of the fifteen resources followed the predicted order of accomplishment, cynicism, and exhaustion in terms of a correlational pattern from strongest to weakest (support from parents, exercise, healthy eating, prayer, and mindfulness), although none of these were significantly and negatively correlated with exhaustion, as would be expected for resources. 
Table 2. Correlations between Resources and Burnout

\begin{tabular}{|c|c|c|c|}
\hline \multirow[t]{2}{*}{ Resources } & \multicolumn{3}{|c|}{ Burnout } \\
\hline & Exhaustion & Cynicism & Accomplishment \\
\hline SP1. Support from administrators & $-.068 *$ & $-.110^{* *}$ & $.104 * *$ \\
\hline SP2. Support from parents & -.009 & $-.102 * *$ & $.117 * *$ \\
\hline SP3. Support from peers & $.088 * *$ & -.037 & $.062 *$ \\
\hline SP4. Support from partner/family & $.146 * *$ & .036 & $.097 * *$ \\
\hline SP5. Support from friends & $.103 * *$ & -.014 & .016 \\
\hline SP6. Instruction on new methods & $.089 * *$ & .012 & $.091 * *$ \\
\hline SP7. Instruction on technology & $.119 * *$ & .000 & $.097 * *$ \\
\hline SP8. Exercise & -.007 & $-.061^{*}$ & $.117 * *$ \\
\hline SP9. Sleep & .049 & .014 & .044 \\
\hline SP10. Healthy Eating & .039 & $-.061 *$ & $.134 * *$ \\
\hline SP11. Meditation & $.066^{*}$ & .021 & $.077 * *$ \\
\hline SP12. Prayer & .007 & -.037 & $.079 * *$ \\
\hline SP13. Counselling/therapy & $.119 * *$ & $.089 * *$ & .005 \\
\hline SP14. Journaling & $.060 *$ & .019 & $.068 *$ \\
\hline SP15. Mindfulness & .013 & $-.068 *$ & $.179 * *$ \\
\hline
\end{tabular}

Note: Higher levels of burnout are indicated by higher levels of exhaustion and cynicism, but lower levels of accomplishment.

**Correlation is significantly different from zero at the .01 level (2-tailed).

*Correlation is significantly different from zero at the .05 level (2-tailed).

\section{Discussion}

In their review of the JD-R model (Bakker \& Demerouti, 2007), Taris, et al. (2017) suggested that one of the model's best features was that it allowed the flexibility to examine various job contexts as well as the specific resources and demands that went with them. Indeed, these authors believed that the model would not fulfil its potential in terms of examination of teaching contexts until studies were conducted where the resources and demands were specifically tailored to that context. The current study not only examines the resources and demands specific to teaching, but also explored the relationships between resources, demands, and burnout in the unprecedented context of teaching during the first wave of the COVID-19 pandemic.

\subsection{Demands of Teaching in a Pandemic}

The findings of the current research offer some support for the JD-R model (Bakker \& Demerouti, 2007) in the teaching context. Both Boldrini et al. (2019) and Taris et al. (2017) suggested that the intensity and nature of a challenge was dependent both on context and on an individual's interpretation, and our research showed that in the teaching context of the 2020 pandemic, specific patterns emerged. Specifically, in four of the five demands examined, the correlations followed the predicted pathway of having the strongest correlation with teacher exhaustion, followed by cynicism, then accomplishment (Alarcon, 2011; Bakker \& Demerouti, 2007). This pattern indicates that the demands of teaching during the pandemic act similarly to one another, as well as to job demands in previous studies where they were treated as subsets of latent variables (Demerouti et al., 2001; Jagodics \& Szabo, 2014). It is interesting that the only demand variable to break this trend is related to lack of resources. Lack of resources was most strongly (negatively) correlated with accomplishment, demonstrating that the greater the perception of a resource deficit, the lower teachers perceived their accomplishment. 


\subsection{Resources for Teachers During a Pandemic}

Likewise, the correlations between resources and burnout were only partially supportive of the expected pattern of the strongest correlations with accomplishment, then cynicism, then exhaustion supported by Alarcon (2011) and Bakker \& Demerouti (2007). Specifically, eight resources - support from parents, professional learning on methods, physical selfcare such as exercise, healthy eating, and emotional self-care such as meditation, prayer, journaling, and mindfulness-were most strongly correlated to accomplishment, as predicted. This indicates a negative relationship between resources and burnout, as has been indicted in previous research when resources were treated as subsets of latent variables (Demerouti, et al., 2001; Jagodics \& Szabo, 2014). One resource was most strongly and negatively associated with cynicism, and that was administrative support. Alarcon (2011) suggested that decreases in accomplishment and increases in cynicism develop concurrently after exhaustion, so these collective findings related to resources are not entirely unexpected. With the exception of administrative support, none of the resources were both significantly and negatively correlated with exhaustion. Six other resources were most strongly and positively correlated with exhaustion, thus behaving in ways that run counter to the JD-R theory (Bakker \& Demerouti, 2007). These resources include support from more intimate relationships such as with partners/families, peers, and friends; therapies such as counselling; instruction in technology; and sleep. Given that most research related to this model predicts that resources will be most strongly correlated with accomplishment or cynicism (Alarcon, 2011), it appears that these six resources are behaving more like demands, in the sense that they all are correlated positively and most strongly with exhaustion. It is possible that the added attention to personal relationships, learning technology, and attending counselling may be perceived as extra stressors by exhausted teachers. Alternatively, it is possible that teachers with high exhaustion perceive personal relationships, instruction with technology, sleep, and therapeutic resources as especially salient and, in that state, seek them out. Given that correlational findings are not necessarily causal, we cannot be sure of the direction of this relationship. This finding is in alignment with Taris et al. (2017), who indicated that perceptions of resources are subjective: the key determination of the classification as a resource or a demand come from the effect, rather than the intent.

The finding that not all intended resources are interpreted by teachers as serving as beneficial may be a result of examining each of the resources in isolation during our analyses. In previous studies, including the original design by Demerouti et al. from 2001, resources were viewed as a latent variable. By collapsing the individual resources into this collective variable or into sets of collective variables, the impact of individual resources is masked. In the 2007 revision of the JDR model (Bakker \& Demerouti, 2007) as well as in the recent review by Taris et al. (2017), there is acknowledgement that a more nuanced examination of resources and demands is needed. In our study, examination of the resources as individual variables revealed that in this design not all resources are perceived as equally supportive and not all intended resources are interpreted as benefits at all by teachers. Although not examined or discussed in a recent study by Jagodics and Szabo (2014), tables presented in their report revealed similar trends. That is, not all resources followed the pattern of being most strongly correlated with accomplishment, followed by cynicism, then exhaustion. Some resources in their study-- such as support from a superior, perceived control, and being provided with feedback-- were most strongly and negatively correlated with exhaustion, while opportunities for growth were most strongly and negative correlated with cynicism.

It is interesting that the resources in our study that involved human relationships were split, with more formal school relationships correlating more strongly to accomplishment (parents) or cynicism (administrators) and the more intimate, perhaps comforting, relationships correlating most closely with exhaustion, although the latter in a positive correlation. These trends are perhaps the best evidence to support the importance of context and personal appraisal proposed by both Boldrini et al. (2019) and Taris et al. (2017). It is intuitive that that teachers with high accomplishment and low cynicism would perceive high support from parents and administrators respectively, and that teachers with high exhaustion might seek out support from their family and friends for comfort during extreme exhaustion. However, these relationships will require more research attention in order to fully understand them and their causal directions.

\subsection{Recommendations for Supporting Teachers}

Together, the findings suggest that an examination of demands, resources, and burnout when teaching during a pandemic generally support the JD-R model in that most demands are more strongly related to exhaustion, followed by cynicism, then accomplishment, as predicted. However, the resources - both contextual and personal—do not always follow the predicted pattern of having the strongest correlation with accomplishment. Depending on the nature of the resources, they are sometimes most strongly correlated with exhaustion. This observation provides us with some tentative direction for supporting teachers in times of change. When teachers are in the initial stages of burnout and exhibiting high exhaustion, our findings suggest that the best way to mitigate the situation may be to decrease demands, as well as provide selected resources. This observation aligns with the advice offered by Taris et al. (2017), who observed that preventing burnout is much easier and more desirable than trying to reverse it. One way to choose the resources is to select those that are most supportive, in that they correlate most strongly and positively with accomplishment or most strongly and negatively with 
cynicism (Alarcon, 2011). The challenge to this approach is that not all of these resources correlate in negative ways with exhaustion (for examples, see support from meditation and instruction on new methods), therefore they may be ineffectual at earlier stages of burnout. Alternatively, the resources could be selected from those that correlate most strongly and negatively with exhaustion, as a pre-emptive measure against further progression in the course of teacher burnout. Interestingly, only one resource correlated negatively and significantly with exhaustion, and that is administrative support. Perhaps the best approach would be to choose resources that do both, in consideration that the system is trying to respond to a collection of teachers and that each may be at a different stage of burnout. Thus, it may be the most effective to provide the resources that are negatively correlated with the teachers' current stage of exhaustion in addition to providing resources that significantly mitigate against loss of accomplishment. The only resource that was negatively and significantly correlated with exhaustion and also most strongly and significantly associated with cynicism and accomplishment was support from administrators. This observation suggests that the support of administrators is significant at all stages of teacher burnout. Furthermore, when teachers are in the final stages of burnout and demonstrating low levels of accomplishment, mitigation might best take the form of more supports from relationships with parents, as well as both physical and emotional self-care practices, as all of these variables behaved as resources in their correlations with accomplishment.

\subsection{Limitations}

All research has limitations, and ours is no exception. First, the data are anonymous and based on self-report. Further validation with data from additional sources would offer greater confidence in the findings. Second, the teachers who took part were self-selected, and it is possible that those who chose not to take part or were unable to take part would have responded differently. Third, the analyses are correlational, and no causal relationships can be predicted based on these findings. The effects of decreasing demands and providing selected resources to the many Canadian teachers currently in the first stages of burnout will be determined by other research — research that is imperative to successful schooling.

As Dorcet, Netolicky, Timmers, and Tauscano stated in their March 2020 report to UNESCO: "We need to acknowledge and plan for disruption in the workforce. If we don't address teacher welfare, we are going to have more collateral problems than answers to this crisis" (p. 10). Determining which demands and resources are most meaningful to preventing teacher burnout during a time of disruptive change like a pandemic will depend on listening to the voices of teachers to ensure that efforts to support them are on the mark and in alignment with the subjective appraisals of those teachers. The current research serves as the first step in that process.

\section{Acknowledgements}

We would like to recognize the support of the Social Sciences and Humanities Research Council of Canada in the form of an Explore grant to the first author. We would also like to acknowledge the assistance of teachers, professional teacher organizations, and faculty members across Canada in distributing our survey.

\section{References}

Alarcon, G. M. (2011). A meta-analysis of burnout with job demands, resources, and attitudes. Journal of Vocational Behavior, 79(2), 549-562. https://doi.org/10.1016/j.jvb.2011.03.007

Al-Fudail, M., \& Mellar, H. (2008). Investigating teacher stress when using technology. Computers \& Education, 51(3), 1103-1110. https://doi.org/10.1016/j.compedu.2007.11.004

Arens, A. K., \& Morin, A. J. S. (2016). Relations between teachers' emotional exhaustion and students' educational outcomes. Journal of Educational Psychology, 108(6), 800-813. https://doi.org/10.1037/edu0000105

Bakker, A. B., \& Demerouti, E. (2007). The job demands-resources model: State of the art. Journal of Managerial Psychology, 22, 309-328. https://doi.org/10.1108/02683940710733115

Boldrini, E., Sappa, V., \& Aprea, C. (2019). Which difficulties and resources do vocational teachers perceive? An exploratory study setting the stage for investigating teacher resilience in Switzerland. Teachers and Teaching, 25(1), 125-141. https://doi.org/10.1080/13540602.2018.1520086

Clunies-Ross, P., Little, E., \& Kienhuis, M. (2008). Self-reported and actual use of proactive and reactive classroom management strategies and their relationship with teacher stress and student behaviour. Educational Psychology, 28(6), 693-710. https://doi.org/10.1080/01443410802206700

Collie, R. J., \& Martin, A. J. (2017). Teachers' sense of adaptability: examining links with perceived autonomy support, teachers' psychological functioning, and students' numeracy achievement. Learning and Individual Differences, 55, 29-39. https://doi.org/10.1016/j.lindif.2017.03.003

Crawford, E., LePine, J., \& Rich, B. (2010). Linking job demands to employee engagement and burnout: A theoretic extension and meta-analytic test. Journal of Applied Psychology, 95(5), 834-848. https://doi.org/10.1037/a0019364 
Demerouti, E., Bakker, A, Nachreiner, F., \& Schaufeli, W. (2001). The job demands-resources model of burnout. Journal of Applied Psychology, 86(3), 499-512. https://doi.org/10.1037/0021-9010.86.3.499

Dorcet, A., Netolicky, D., Timmers, K., \& Tuscano, F. (2020). Thinking about pedagogy in an Unfolding Pandemic: In Independent report to Written to Inform the work of Education International and UNESCO. http://issuu.com/educationinternational/docs/research/2020_covid-19_eng

Eddy, C., Herman, K., \& Reinke, W. (2019). Single-item teacher stress and coping measures: Concurrent and predictive validity and sensitivity to change. Journal of School Psychology, 17-32. https://doi.org/10.1016/j.jsp.2019.05.001

Harmsen, R., Helms-Lorenz, M., Maulana, R., \& van Veen, K. (2018). The relationship between beginning teachers' stress causes, stress responses, teaching behaviour and attrition. Teachers and Teaching, 24(6), 626-643. https://doi.org/10.1080/13540602.2018.1465404

Holmes, E., O'Connor, R., Perry, V., Tracey, I, Wessly, S., Arseneault, L., ... Ballard, C. (2020). Multi-disciplinary research priorities for the COVID-19 pandemic: a call for action for mental health sciences. Lancet Psychiatry, 7, 547-560. https://doi.org/10.1016/S2215-0366(20)30168-1

Jagodics, B., \& Szabo, E. (2014). Job demands versus resources: Workplace factors related to teacher burnout. Theory and Research in Education, 9(4), 377-390.

Jennings, P. A., \& Greenberg, M. T. (2009). The prosocial classroom: Teacher social and emotional competence in relation to student and classroom outcomes. Review of Educational Research, 79, 491525. https://doi.org/10.3102/0034654308325693

Johnson, S., Cooper, C., Cartwright, S., Donald, I., Taylor, P., \& Millet, C. (2005). The experience of work-related stress $\begin{array}{lllll}\text { across occupations. Journal of Managerial Psychology, 20(2), } & \text { 178-187. }\end{array}$ https://doi.org/10.1108/02683940510579803

Klusmann, U., Richter, D., \& Lüdtke, O. (2016). Teachers' emotional exhaustion is negatively related to students' achievement: Evidence from a large-scale assessment study. Journal of Educational Psychology, 108, 1193 https://doi.org/10.1037/edu0000125

Kyriacou, C. (2001). Teacher stress: Directions for future research. Educational Review, 53(1), 27-35. https://doi.org/10.1080/00131910120033628

Maslach, C., \& Jackson, S. E. (1981). The measurement of experienced burnout. Journal of Occupational Behaviour, 2 , 99-113. https://doi.org/10.1002/job.4030020205

Maslach, C., Jackson, S. E., \& Schwab, R. L. (1996). Maslach Burnout Inventory - Educators Survey (mbi-es). In C. Maslach, S.E. Jackson, \& M.P. Leiter, MBI Study (3d ed). Palo Alto, CA: Consulting Psychologists Press.

Maulana, R., Helms-Lorenz, M., \& van de Grift, W. (2015). Development and evaluation of a questionnaire measuring pre-service teachers teaching behaviour: A Rasch modelling approach. School Effectiveness and School Improvement, 26, 169-194. https://doi.org/10.1080/09243453.2014.939198

McCarthy, C. J., Lambert, R. G., Lineback, S., Fitchett, P., \& Baddouh, P. G. (2015). Assessing teacher appraisals and stress in the classroom: Review of the classroom appraisal of resources and demands. Educational Psychology Review, 28, 577-603. https://doi.org/10.1007/s10648-015-9322-6

Ott, M., Hiebert, K., Rodger, S., \& Leschiel, A. (2017). A well place to be: The intersection of Canadian school-based mental health policy with student and teacher resiliency. Canadian Journal of Education, 40(2), 1-30. https://journals.sfu.ca/cje/index.php/cje-rce/article/view/2243/2422

Skaalvik, E. M., \& Skaalvik, S. (2015). Job satisfaction, stress and coping strategies in the teaching profession - What do teachers say? International Education Studies, 8, 181-192. https://doi.org/10.5539/ies.v8n3p181

Taris, T., Leisink, P., \& Schaufeli, W. (2017). Applying occupational health theories to educator stress: Contributions of the jobs-demands resources model (pp. 237-260). In T. McIntyre, S. McIntyre, and D. Francis (Eds), Educator Stress: An Occupational Health Perspective. Huston, TX: Springer. https://doi.org/10.1007/978-3-319-53053-6_11

Van Veldhoven, M. (1996). Psychosociale arbeidsbelasting en werkstress [Psycho-social workpressure and workstress]. Doctoral thesis, Rijksuniversiteit Groningen, Groningen, The Netherlands.

\section{Copyrights}

Copyright for this article is retained by the author(s), with first publication rights granted to the journal.

This is an open-access article distributed under the terms and conditions of the Creative Commons Attribution license which permits unrestricted use, distribution, and reproduction in any medium, provided the original work is properly cited. 